over the next five years which is required to implement fully the Department's present programme of work.

After discussions with the University Research Committee and the chairman of the new University Grants Committee the Council proposes to terminate the present type of research grant made to the universities by the Department. From the end of the present financial year the Department will sponsor and provide funds for research units in universities in fields of study deemed essential in the national interest, and in which an outstanding man is stationed in the university, and by entering into research contracts with universities. Grants to research and allied institutions in 1960-61 amounted to $£ 176,862$, of which $£ 33,810$ was to universities and agricultural colleges and $£ 91,376$ to research associations.

The Council's recommendation for the establishment of a new Wool Research Organization as an incorporated research association with an annual income of $£ 100,000$, half from the New Zealand Wool Board and half from the Government has been approved, and the new buildings for the Meat Research Institute were completed during the year. The Council has decided to continue New Zealand's scientific programme in Antarctica at about its present level ( $£ 86,606$ in 1960-61), and topographical and geological survey work will be continued until the reconnaissance of the Cape Adare-Beardmore section is complete. Some concerm is expressed as to the effect of delay in developing the Institute of Nuclear Sciences on the research programme in this field.

Points in the research work completed during the year noted in the Secretary's report include the completion of the first volume of the new Flora of New Zealand; the high yields now being obtained with Aotca wheat, bred at the Crop Research Division and released in 1957; the marked difference in the distribution of radioactive selenium in plants; the variation of the nitrate-levels and of sodium, potassium, calcium, manganese, aluminium, copper, titanium, iron, zinc, sulphate and phosphate in ryegrass plants, and the study of the systematics and taxonomy of bacterial plant pathogens.
The Fruit Research Division's apple-variety collection has led to the selection of the Canadian variety Spartan and a local seedling, Red Fresca, for extensive commercial trial, and satisfactory drying of tobacco leaf has been obtained by two methods which enable a kiln to be loaded with much less labour and permit the use of smaller kilns. A study has been made of the Adelie penguins breeding at Cape Royds, Ross Island; and a set of 54 soils selected representing a range of New Zealand soils for agricultural, forestry and highway purposes is being examined comprehensively by chemical physical and biological tests.

An intensive mineralogical study of volcanic ash showers has been commenced, and the four-mile geological map project commenced in 1956 to be completed in 1964 has already indicated areas meriting more detailed examination. A rugged tester, in which the sample is dried for $5 \mathrm{~min}$. in hot air and weighed on scales calibrated directly in water content (corrected for buoyancy) has been developed by the Dominion Laboratory, and 20 of these machines are now in use in scouring works and freezing works throughout New Zealand for controlling the drying of wool. A fœetal heart-rate recorder has been constructed using a heart-sound pick-up which dolivers this conglomeration of sounds to a system specially designed to deal with a foetal pulse which may be mostly even below the level of background noise. Investigations of the variation in the essential oil derived from semples of Pinus radiata have been initiated, and an instrument developed for rapidly and accurately determining the density of a wood sample taken from a living tree, utilizing a very narrow beam of beta-radiation from a strontium-90 source. A novel type of navigation light for merking narrow channels has been developed which can be used when the configuration of the land in line with the channel will not permit the use of more than one light. An emergency wheat-testing service provided by the Wheat Research Institute avoided substantial loss during the 1961 wheat harvest. A survey of currents in McCurdo Sound established that at least in summer there is a definite movement of water towards the Antaretic Ice Shelf.

\title{
FOOT-AND-MOUTH DISEASE
}

$\mathrm{I}_{\mathrm{Dr}}^{\mathrm{N}}$

$N$ a report issued by the Research Institute (Animal Virus Diseases), Pirbright, Surrey*, the director, Dr. I. A. Galloway, describes the investigations made into foot-and-mouth and related virus diseases over the past five years.

The research programme of the Institute is considered in relation to foot-and-mouth disease in Britain, and, in turn, as a world problem. In Britain, periods of relative freedom from the disease (or at least of low incidence) are interrupted by times when as many as 200 farms may become infected in one month. These periods of higher incidence do not generally last more than three or four months, and the number of animals involved in relation to the animal population of the country remains less than half of 1 per cent. It is generally agreed that a vaccination programme against the disease in a country where it is endemic is unlikely to reduce the

- Research Institute (Animal Virus Diseases), Pirbright. Report for the years 1956-1960. Pp. 52. (Plrbright, Surrey: Research Institute (Animal Virus Diseases), 1961.) 28. $6 d$. incidence much below this figure. If, therefore, the disease were allowed to become endemic in Britain, and vaccination were decided on, the ultimate goal which could reasonably be achieved would be an incidence equivalent to that which now obtains. At that point, a slaughter policy would undoubtedly be invoked to attempt to achieve eradication of the disease. If the situation in the European countries is considered, it is seen that, in spite of an increasing extension of vaccination since the 1951-52 epidemic, the incidence of the disease, though greatly reduced, is still somewhat higher than in Britain. Some countries are applying, and others considering, limited slaughter of infected animals as a further step towards eradicating the disease. Outside Europe, in endemic areas, effective control of the disease is still some way off, and it is here perhaps that the new improved vaccines have the greatest part to play, if the cost of the vaccination campaign can be reduced and the efficiency of the vaccine increased. Assistance in reduction of the incidence of the disease elsewhere 
than in Britain is at present the greatest contribution which can be made towards the control of the disease within the country.

A considerable proportion of the research effort at Pirbright has always been directed at improved methors of immunization against the disease. The period under review has seen a new bias on work on immunization. The development of live modified strain vaccines received a new impetus by the demonstration by Skinner in 1951 of the possibility of infecting unweaned mice and, in 1954, of passaging virus in day-old chicks and chick embryos. Serial transfers, repeated sometimes many hundreds of times, have the effect of reducing the capacity of the virus to produce visible signs of the disease in the cattle inoculated. By multiplying in the animal, however, the virus would stimulate the defence mechanism of the host and so produce a solid longlasting immunity. Such vaccines are used in many other diseases; for example, in rinderpest, rabies, Afriean horse sickness, blue tongue, and in yellow fever and also in smallpox in man. Workers developing such strains aim at the point at which the virus will 'infect' the animal but produce no clinical signs. The yellow fever vaccine inoculated in man is an example of a live virus vaccine which has reached this point. With most live vaccines, the ideal is not attained, and a compromise between slight infectivity in the sense of producing the clinical disease on one hand, and a capability which falls short of the maximum in producing immunity on the other, has to be accepted. This has been true in developing the strains in foot-and-mouth disease and the problem has been made more difficult by the demonstration that not all strains become attenuated or lose virulence at the same rate. On the other hand, there has been little indication of difficulty in some other ways; for example, there has been no restoration of virulence and no spread to normal animals in contact with those vaccinated. Limited experiments on pregnant animals have indicated no unfortunate sequelæ, and young animals have been successfully vaccin. ated.

The variation in behaviour of viruses has made the development of suitable strains for each of the seven types of virus now known a complicated operation, especially when several different strains of one type have had to be developed to explore the possibilities of different methods of attenuation. Nevertheless, strains of six of the seven types have reached the point at which tests for non-infectivity in cattle have been sufficiently encouraging to warrant investigations on the immunity produced. These tests at Pirbright have now involved approximately 2,000 animals.

The qualified successes obtained under experimental conditions at Pirbright led to the next phase in development of these strains. Since the step from the laboratory to field conditions might not be without risk, it was considered that first trials outside the laboratory should be conducted in areas where the disease was endemic. The Institute has had the willing and enthusiastic co-operation of the Governments of countries in South and East Africa in a series of trials. These experiments have indicated the potential usefulness of suitable strains in such animal populations while, at the same time, bringing to light many of the suspected difficulties inseparable from immunization of a mixed population with possible previous experience of the disease. Some of these experiments, notably those in South Africa, have involved tests of live attenuated vaccine on a scale which has not been undertaken with any other agent of this type, in respect of severe challenge with fully virulent material. Even under these conditions, 70 per cent protection was obtained and subsequent use of the vaccine in an infected area resulted in an incidence of less than 1 per cent on vaccinated farms, while, on unvaccinated farms, the incidence was between 60 and 70 per cent. These observations are essentially preliminary; many problems require investigation.

The problem of the use of inactivated vaccines has not been neglected. Frenkel-type vaccine in which virus is grown in culture of cattle tongue epithelium, adsorbed on aluminium hydroxide and inactivated with formalin and mild heat, has been a useful agent and will continue to play a most important part in the control of the disease as it has done in Europe and, to some extent, in South America. Extensive tests of this type of vaccine have been carried out at Pirbright and several large batches have been prepared and tested for safety and potency. Other possible sources of tissue in which virus may be grown, such as kidney, are being investigated, since kidneys present a more easily obtainable source of tissue than cattle tongue epithelium.

Foot-and-mouth disease must be considered as a world problem. Part of the work at Pirbright, therefore, has been directed towards the assessment of the world situation, particularly in regard to the prevalence of the disease and the distribution of the inmunological types of virus. Farlier reports have referred to the discovery at Pirbright of four new typesS.A.T. 1, S.A.T. 2 and S.A.T. 3 from Africa, and Asia 1 in many countries in Asia. In the past twelve years considerable progress has been made in determining the broad outlines of type distribution. The international importance of this work was recognized when, in 1958, the Institute was nominated by the Food and Agriculture Organization of the United Nations to undertake the functions of World Reference Laboratory for Foot-and-Mouth Disease.

\section{APPLIED GEOGRAPHY}

T HE application of geography to the study of a wide range of problems has made remarkable progress in recent years, partly during, and partly because of. the Second World War. Geography made a substantial contribution to the British War effort both in the planning of campaigns and in the reorganization of the nation's economy, and since the
War geographers have been active in the field of planning. Some of the fruits of these efforts can now be seen in the increase in the number of geographers who act as advisers in various fields, ranging from problems of conservation to aspects of medical geography: there is also the evidence of the results achieved by those who have been largely employed in the study of 